\title{
Gestão por competências: um estudo de caso sobre a implementação do projeto no Tribunal de Contas da União - TCU*
}

\author{
Management skills: a case study on the \\ implementation of the Project In The Brazilian \\ Count of Audit - TCU
}

Thais Da Silva Ribeiro' Erika Costa Vieira Gagliardi
Recebido em: 05/02/2013

Aprovado em: 06/11/2013

1 Formada em Administração pelo Centro Universitário de Brasília - UniCEUB. E-mail: thais. ribeiro@hotmail.com.br.

2 Mestre em Gestão do conhecimento e Tecnologia da Informação pela Universidade Católica de Brasília, pós-graduada em Administração de Recursos Humanos pela FGV, graduada em Administração. Professora universitária no UNICEUB, professora no ensino a distância, atuação em empresas privadas na área de gestão de pessoas e consultoria empresarial na área de Gestão de Pessoas. Também atua como coach. E-mail: erika.gagliardi@uniceub.br

\section{Resumo}

O termo competência é relativamente novo no mundo organizacional e teve o seu surgimento associado às mudanças crescentes no mercado que se tornou cada vez mais competitivo. Diante dessa nova realidade as empresas começaram a repensar todo o seu sistema de gestão. Foi nesse período que o conhecimento começou a ser valorizado dentro das empresas, fazendo-as selecionar e reter funcionários cada vez mais capacitados. Assim, a gestão por competência nasce com a proposta de alinhar as competências humanas às organizacionais, nas quais se busca o alcance dos objetivos estratégicos e, consequentemente, melhores resultados. Nesse contexto, o artigo se propõe a apresentar uma previsão de resultados esperados de melhoria com a utilização do modelo de gestão por competência no Tribunal de Contas da União - TCU. Para tal, além de uma revisão de literatura acerca do termo competência, foi realizada uma entrevista com os responsáveis pelo projeto. Ao final, foi possível verificar que o projeto começou a ser implementado em determinadas áreas, demonstrando resultados positivos, porém ainda pequenos. Entretanto, as expectativas dos resultados ao término da implementação do processo são as melhoras possíveis. Em suma, espera-se que o modelo consiga integrar os processos de gestão de pessoas, para que o TCU possa alcançar de maneira mais positiva os resultados organizacionais e os seus objetivos estratégicos.

Palavras-chave: Competência. Gestão por competência. Gestão de pessoas. Tribunal de Contas da União. Resultados e objetivos organizacionais.

\section{Abstract}

The term competence is relatively new in the organizational world and had its emergence associated the increasing changes the market which become increasingly competitive. Faced with this new reality companies began to rethink your entire management system. It was during this period that knowledge begins to be valued within companies making these businesses select and retain qualified employees increasingly. Thus, management by competence born with the proposal to align the human skills to organizational in which one seeks the achievement of strategic objectives and, consequently, better results. In this context, this paper aims to present a preview of results expected to improve with the use of competency management model by the 
Brazilian Count of Audit - TCU. To this end, beyond of a literature review of the term competence, an interview was conducted with those responsible for the project. At the end, was possible to verify that the project began to be implemented in certain areas, showing positive results, but still small. In the meantime, expectations of the results at the end of the implementation process are the best possible. In short, it is expected that the model can integrate the processes for managing people, so that TCU can achieve more positively organizational results and strategic objectives.

Key-Words: Racing. Management by competence. People management. Brazilian Count of Audit. Results and organizational objectives.

\section{Introdução}

O presente estudo se refere a gestão por competência. Bitencourt et al. (2010), lembram em sua obra que o tema não é recente, entretanto vem tomando mais espaço no meio acadêmico e empresarial devido às novas abordagens estratégicas adotadas pelas organizações. Umas das explicações citadas pelos autores para esse novo fenômeno é o treinamento tradicional, no qual é possível perceber que ele já não supre as necessidades de formação dos novos funcionários fazendo com que, consequentemente, as organizações não alcancem as suas necessidades e expectativas exigidas em um mercado altamente competitivo.

Assim, os autores afirmam que empresas contemporâneas visam gestões que as ajudem em um novo contexto de mercado, tendo como objetivo a eficácia dos recursos produtivos e a adequação das pessoas ao trabalho, garantindo excelência organizacional. "Nesse sentido, a gestão de competência, visa aproximar os objetivos organizacionais e pessoais (profissionais)" (BITENCOURT et al., 2010, p. 176).

Colaborando com essa ideia, Carbone et al. (2009) afirmam que as empresas vêm adotando a gestão por competência como forma de planejar, captar, desenvolver e avaliar o indivíduo, o grupo ou a organização de acordo com as competências necessárias para o alcance dos objetivos organizacionais. Sendo assim, é imprescindível que as competências estejam aliadas à missão e aos objetivos organizacionais.
Este trabalho justifica-se pela curiosidade em estudar um órgão da administração pública, que vem passando por processos de mudanças significativas para a nova administração. O TCU vem adaptando os seus processos de gestão de pessoas aos objetivos e às estratégias da organização. Um desses processos é a gestão do modelo por competência, que tem como finalidade desenvolver as competências de cada indivíduo, de acordo com as competências essenciais à organização. (DUTRA, 2008).

Partindo desse ponto, o TCU vem tentando gerir melhor os seus recursos humanos, o que consequentemente os leva a uma maior satisfação e motivação no ambiente de trabalho, ocasionando principalmente resultados mais eficazes.

Espera-se que este artigo aponte o Tribunal de Contas da União como órgão pioneiro, um modelo a ser seguido por outros órgãos da administração pública, de forma a gerar resultados mais significativos, não só para o Órgão como empresa, mas também para a sociedade e o Estado.

Tendo em vista o que foi mencionado, o tema deste artigo é gestão por competência, um estudo de caso sobre a implementação do projeto no Tribunal de Contas da União - TCU. O artigo se norteia pelos problemas: Quais as expectativas dos servidores responsáveis pelo projeto de gestão por competência em relação aos resultados futuros da sua implementação? O objetivo é apresentar uma previsão de resultados esperados de melhoria com a utilização do modelo de gestão por competência no TCU. Ao final, pretende-se comparar os resultados encontrados com a teoria de base, avaliando se o modelo de gestão por competência agrega valores à gestão do TCU.

Para isso, em um primeiro momento, este estudo refletirá sobre o surgimento e sobre a evolução do termo competência, conceituando-a de acordo com os principais autores na área. Posteriormente, será trabalhada a gestão por competência, explicando suas características e quais os benefícios para as organizações, além de apresentar os modelos mais utilizados por ela. Em um segundo momento, será realizada uma entrevista semiestruturada entre os servidores responsáveis pelo projeto, com o objetivo de coletar suas expectativas. Após a coleta de dados, será realizado um estudo de categorização de perguntas e respostas. Por meio de palavras-chave será determinada a frequência e a valência de cada categoria. Finalmente, 
serão selecionadas e apresentadas as expectativas vistas como as mais importantes à implementação do modelo de gestão por competência no TCU.

\section{Revisão de literatura}

\subsection{Competências}

Brandão (2009) refere-se à origem do termo competência como sendo expresso inicialmente na Idade Média, pertencente ao linguajar jurídico. Seu significado dizia respeito à faculdade atribuída à pessoa ou instituição, dando-lhe autoridade para julgamento. Ao longo do tempo, a expressão competência associou-se à capacidade do indivíduo debater sobre determinados assuntos. E por fim, tem-se o significado de competência como atributo dado a alguém capaz de realizar certos trabalhos, sejam eles em âmbito organizacional ou não.

O termo competência nasce dentro das organizações em meio à crise que se instalou no mundo econômico em meados dos anos 1970, devido aos avanços tecnológicos que resultaram em demissões em massa e na crescente competitividade organizacional. Diante dessa nova realidade, as empresas começaram a repensar todo o seu sistema de gestão, procurando por um ponto de equilíbrio entre a redução dos custos e as alternativas de receita. Assim, era necessário encontrar modelos de gestão que suprissem essas necessidades. Foi, então que, em 1982, Richard Boyatizis com sua obra The competent Manager: a Modal for effective Performance, introduziu o tema competência dentro das organizações, o que, posteriormente, diante de discussões envolvendo inúmeros teóricos, transformou-se na gestão por competência, uma prática gerencial (BITENCOURT et al., 2010.).

Le Boterf (2003 apud BITENCOURT et al., 2010) afirma que a noção de competência se desenvolveu em um período de crescente competitividade organizacional, em que as empresas procuravam conciliar os recursos incorporados à pessoa como: conhecimentos, habilidades, experiências e qualidade aos recursos presentes no meio, como bancos de dados, redes documentares etc.

Mediante uma necessidade das organizações de suprirem as exigências organizacionais e do mercado, o termo competência tornou-se frequente como forma de selecionar e reter colaboradores que detenham compe- tências raras, valiosas e difíceis de serem desenvolvidas, além de conferirem à organização um desempenho superior ao de seus concorrentes, capazes de desenvolver competências fundamentais à consecução dos objetivos organizacionais (DURAND, 2000; PRAHALAD; HAMEL, 1090 apud CARBONE et al., 2009).

Assim, o termo sendo frequentemente utilizado em um contexto organizacional, vários conceitos foram sendo criados ao longo dos anos, mas todos eles seguindo o mesmo raciocínio. Para Dutra e Silva (1998 apud BITENCOURT et al., 2010, p. 181), competência é:

Capacidades da pessoa gerar resultados dentro dos objetivos estratégicos e organizacionais da empresa, traduzindo-se pelo mapeamento do resultado esperado (output) e do conjunto de conhecimentos, habilidades e atitudes necessários para o seu alcance (input).

Para Fleury e Fleury (2000 apud BITENCOUT et al., 2010, p. 181), competência pode ser conceituada por:

Um saber agir responsável e reconhecido, que implica mobilizar, integrar, transferir conhecimentos, recursos, habilidades que agreguem valor econômico à organização e valor social ao indivíduo.

Por fim, Carbone et al. (2009, p. 43) apontam competência de:

Combinações sinérgicas de conhecimentos, habilidades e atitudes, expressas pelo desempenho profissional dentro de determinado contexto organizacional, que agregam valor a pessoas e organizações.

Percebe-se uma semelhança entre os autores citados, entretanto é possível notar a existência de duas grandes correntes: a primeira de origem norte-americana, representada principalmente por McClelland (1973) e outra de origem francesa, representada por Le Boterf (1999) e Zarifian (1999). A diferença entre essas correntes está na percepção da palavra competência. Para a corrente norte-americana, ter competência significa credenciar as pessoas a exercerem determinado trabalho; já a corrente francesa considera competência um conjunto de realizações da pessoa em um determinado contexto.

Podemos concluir então que Dutra e Silva (1998) seguem uma linha francesa. Já Fleury e Fleury (2000) possuem um posicionamento norte-americano. Para Carbone et al. (2009), o conceito de competência foi construído partindo tanto da premissa norte-americana quanto da francesa. 
No entanto, independentemente das origens, o termo competência exerce apenas um sentido no mundo empresarial: ser capaz de fazer algo.

Brandão (2009) afirma que o desenvolvimento das competências nos seres humanos ocorre por meio da aprendizagem, seja ela aprendida naturalmente ao longo dos anos ou induzida formal ou informalmente. Desse modo, a partir do conhecimento adquirido por meio da aprendizagem, o indivíduo deve possuir habilidades que evidenciem o conhecimento alcançado, gerando experiências e atitudes que motivem seu comportamento.

Desse modo, Carbone et al., (2009) relacionam o conhecimento a informações obtidas e reconhecidas que são internalizados pelo indivíduo, assim, causando impacto sobre decisões, julgamentos ou comportamentos. Nesse sentido, representa tudo o que foi acumulado ao longo de sua vida.

Já a habilidade é entendida por Carbone et al., (2009) como uma aplicação produtiva do conhecimento. Durand (2000 apud BRANDÃO, 2009, p. 11) afirma que a habilidade "[...] diz respeito à capacidade da pessoa de fazer uso produtivo do conhecimento que detém”, ou seja, é a capacidade de o indivíduo colocar em prática seus conhecimentos armazenados ao longo dos anos.

Com relação à atitude, o referido autor a define como sendo iniciada por estímulos que levam o individuo a agir em determinada circunstância. $\mathrm{O}$ autor afirma ainda que as atitudes representam os interesses do indivíduo, relacionados às suas preferências e sentimentos.

Conhecimento, habilidades e atitudes podem ser vistos como recursos ou dimensões da competência. Carbone et al., (2009) as pressupõem como necessárias para o desempenho individual no trabalho.

Prahalad e Hamel (1990, apud CARBONE et at., 2009) afirmam que o conceito de competência nas organizações refere-se à capacidade da organização de se tornar eficaz. Assim, atribuem à competência o termo essencial, ou seja, as competências essenciais à organização, aquelas capazes de atribuir valor percebido pelo cliente, gerando assim vantagem competitiva difícil de ser imitada pelos concorrentes.

Diante disso, é possível classificar as competências em individual e organizacional. A primeira, quando assume a capacidade da pessoa e a segunda, como atributos e capacidade de um grupo ou da organização como um todo (CARBONE et al., 2009).

\subsection{Gestão por competência}

Carbone et al., (2009) afirmam que a gestão por competência nasce com a proposta de alinhar as competências humanas às organizacionais, havendo assim uma sustentação entre elas, proporcionando o alcance dos objetivos estratégicos das organizações.

Somando a isso, Brandão e Babry (2005) afirmam que a gestão por competência foi apontada como um modelo de gestão alternativa capaz de deter o domínio de colaboradores mais bem preparados e capacitados para a realização das funções do cargo, de forma a proporcionar à empresa maior vantagem competitiva. Brandão e Guimarães (2001) salientam que a gestão por competência tem que estar alinhada ao plano estratégico da organização em que, consequentemente, formará um subsistema da gestão organizacional. Dessa forma, a empresa necessita contar com uma gestão estratégica de recursos humanos, de forma a promover o desenvolvimento de habilidades, produzir relações sociais e criar conhecimento, ou seja, desenvolver competências.

A gestão por competência tem como objetivo captar, desenvolver e avaliar as competências essenciais, que suprem as necessidades organizacionais (BRANDÃO; GUIMARÃES, 2001 apud BRANDÃO; BABRY, 2005). Por esse motivo, a área estratégica de gestão de pessoas auxilia a gestão por competência, recrutando, selecionando e treinando seus colaboradores, a fim de desenvolver as competências essenciais de forma a alcançar os objetivos e garantir à organização a consistência de sua estratégia (BRANDÃO; GUIMARÃES, 2001).

Percebe-se que a gestão por competência deve ser vista de forma sistêmica, envolvendo diversos níveis da organização, seja o corporativo ou individual, divisional ou grupal. Para isso, é imprescindível que ela esteja em harmonia com a gestão estratégica da organização, ou seja, missão, visão e objetivos. Dessa forma, o que se deseja alcançar pela organização, por meio dos seus objetivos estratégicos, estará atrelado e orientado pela captação e pelo desenvolvimento das competências (BRANDÃO; GUIMARÃES, 2001).

Fernandes e Fleury (2007) afirmam que o modelo de gestão por competência passou por uma evolução. 
Foram identificadas quatro gerações distintas: a visão comportamental, a competência como input, a incorporação da complexidade e a visão abrangente. A primeira, visão comportamental, refere-se aos trabalhos elaborados por McClelland em consultoria a McBer. Nessa primeira geração, a proposta é identificar características ideais de profissionais bem sucedidos, assim replicando a fórmula de sucesso aos demais colaboradores da organização.

A geração da competência como input foi trabalhada em uma consultoria feita na Coopers \& Lybrand. O modelo partia de definições que correlacionavam conhecimento, habilidades e atitudes que afetavam consideravelmente as atividades de alguém. Assim, era possível definir as competências inerentes ao cargo e, posteriormente, avaliar se elas eram desempenhadas pelos funcionários. A terceira geração incorpora a complexibilidade às competências, de forma a descrever as competências de acordo com o seu nível de complexidade. Esse modelo vem sendo utilizado pela Unilever, desde 1994 (FERNANDES; FLEURY, 2007).

Por fim, a quarta geração compreende uma visão abrangente, ou seja, utiliza conceitos de competência, de complexidade, de espaço ocupacional e de agregação de valor. Esse modelo, utilizado por Dutra (2010), menciona competência como não sendo estática, ou seja, à medida que o colaborador se desenvolve dentro da organização, novas atribuições lhe são destinadas, de maior complexidade, que geram o aumento do seu espaço ocupacional $\mathrm{e}$, consequentemente, transformando-o em um recurso mais valioso para a empresa. Dessa forma, a organização retém valor ao negócio, proporcionando melhor vantagem competitiva (FERNANDES; FLEURY 2007).

Para Dutra, Hipólito e Silva (2000), a concepção do modelo consiste em traçar eixos conforme a natureza do trabalho e subdividi-los em características de complexidade, correlacionando-os aos resultados esperados. Após esse processo, é definido um conjunto de conhecimentos e experiências que se fazem necessários à obtenção dos resultados. Assim, é possível relacionar o que é cobrado do colaborador e quais são os seus conjuntos de competências, resultando no que ele consegue proporcionar à organização.

Dutra (2010) menciona que o modelo é composto por um processo no qual existem inputs e outputs, que representam respectivamente um conjunto de conheci- mentos, de habilidades e de atitudes e a agregação de valor ao final do processo.

É possível, por meio da figura abaixo identificar a estrutura básica do modelo de Dutra (2010) composto pelos autores mencionados.

Figura 1- Estrutura Básica do Modelo baseado em competências

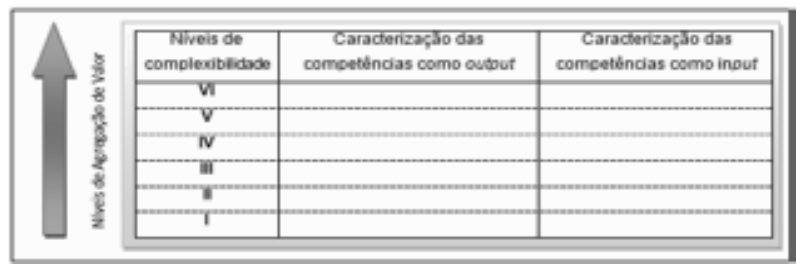

Fonte: Dutra, Hipólito e Silva (2000), com adaptações.

Baseado no modelo exposto, o autor afirma que “[...] a agregação de valor das pessoas é, portanto, sua contribuição efetiva ao patrimônio de conhecimento na organização, permitindo-lhe manter suas vantagens competitivas no tempo" (DUTRA, 2010, p. 29).

Outro modelo conhecido e que será exemplificado a seguir é o proposto por Guimarães (2001 apud CARBONE et al., 2009).

Para esse autor, o Modelo de Gestão por Competência, que pode ser visualizado na Figura 2, inicia-se na formulação da estratégia organizacional, como já mencionado anteriormente. Nessa fase, a organização tem a oportunidade de definir missão, visão e objetivos futuros, ou seja, discorrer sobre qual o propósito principal de existência da empresa; como esse propósito pode ser alcançado, de forma a representar as vontades futuras da organização; e qual caminho ela seguirá. Dessa forma, espera-se definir os indicadores de desempenho e metas, identificando as competências necessárias a fim de proporcionar à organização o alcance da missão, da visão e dos objetivos, ou seja, o desempenho esperado.

Diante disso, Carbone et al. (2005 apud BRANDÃO; BABRY, 2005) afirmam que a organização possuidora da estratégia de mercado formulada tem possibilidade de mapear e estruturar melhor as competências necessárias a cada cargo, posto que, uma vez formulada a estratégia, a organização consegue identificar aonde ela quer chegar e, principalmente, o que deve ser feito e como deve ser feito para o alcance desses objetivos.

Depois de realizadas as etapas de formulação da estratégia organizacional, são definidos os indicadores de 
desempenho e diagnósticos das competências essenciais à organização. Os autores mencionam que deve ser feito o mapeamento das competências organizacionais e humanas ou individuais. $\mathrm{O}$ mapeamento identifica as lacunas entre as competências necessárias ou essenciais e o alcance do desempenho esperado mediante as competências humanas ou individuais já existentes na organização.

O passo inicial do mapeamento de competências consiste em identificar as competências essenciais e individuais; para esses autores, a identificação é feita inicialmente por meio de pesquisa documental, incluindo a análise de conteúdo da missão, da visão e dos objetivos da estratégia organizacional. Posteriormente, é feita uma coleta de dados com pessoas chave da organização. Obtidas as duas informações, é feito um emparelhamento entre elas, para assim, obter as competências em falta na organização (BRUNO-FARIA; BRANDÃO, 2003 apud BRANDÃO; BABRY 2005).

De forma resumida, o mapeamento de competências ao seu final deve representar um desempenho ou comportamento do que é esperado pelo profissional, ou seja, o que ele deve ser capaz de fazer (BRANDÃO; BABRY 2005).

Após o diagnóstico das competências, a organização deve ser capaz de desenvolver as competências internas.

Ao se fazer o planejamento, é possível identificar quais os tipos de competências a organização necessitará. Desse modo, o recrutamento e a seleção, bem como o treinamento, desenvolvimento, avaliação de desempenho e remuneração estarão voltados e atrelados ao modelo de gestão por competência, com o intuito de obter os resultados organizacionais esperados.

Assim, de acordo com os autores supracitados, o modelo consegue identificar quais competências estão em falta causando prejuízo à organização; são as chamadas "lacunas" de competência. A organização, após a identificação dessas "lacunas", tem a oportunidade de desenvolver a carência dessas competências. Entretanto, a ausência do desenvolvimento dessas competências tende apenas a aumentar essas lacunas.

Constantemente, novas competências são exigidas no mercado, devido a atual complexidade do ambiente em que as empresas estão inseridas. Sejam competências pessoais ou organizacionais, ambas podem tornar-se obsoletas; por esse motivo, é fundamental o constante desenvolvimento de competências, bem como a captação de novas competências (BRANDÃO; BABRY 2005).

O modelo segue pelo processo de captação e integração de competências externas. A integração acontece individualmente, por meio de recrutamento e seleção, e nas organizações, por meio de ações como o joint-venture ou alianças estratégicas (BRANDÃO; GUIMARAES, 2001 apud CARBONE et al., 2009).

Passando por essas etapas, os autores citados afirmam que é possível elaborar planos operacionais de trabalho e gestão capazes de identificar o desempenho e grau de complexidade de cada cargo, a fim de remunerar equipes e indivíduos de acordo com a obtenção dos resultados esperados.

Por fim, Carbone et al. (2009) sugerem que ao final do processo seja feito acompanhamento e avaliação dos resultados alcançados, comparando-os com os esperados. Comparam-se também as mudanças sofridas após a implementação do modelo, os resultados obtidos antes e depois de sua implementação. Durante essa avaliação, é verificado se as ações adotadas pela organização foram eficazes em promover e em desenvolver as competências. Essa fase é o retroalimentador do sistema. É ela quem ajuda subsidiar novas etapas do processo, garantindo informações capazes de movimentar o modelo de gestão por competência.

A seguir, será exposto o fluxo do modelo de gestão por competência proposto por Guimarães (2001 apud CARBONE et al. 2009). 
Figura 2: Modelo de Gestão por Competência

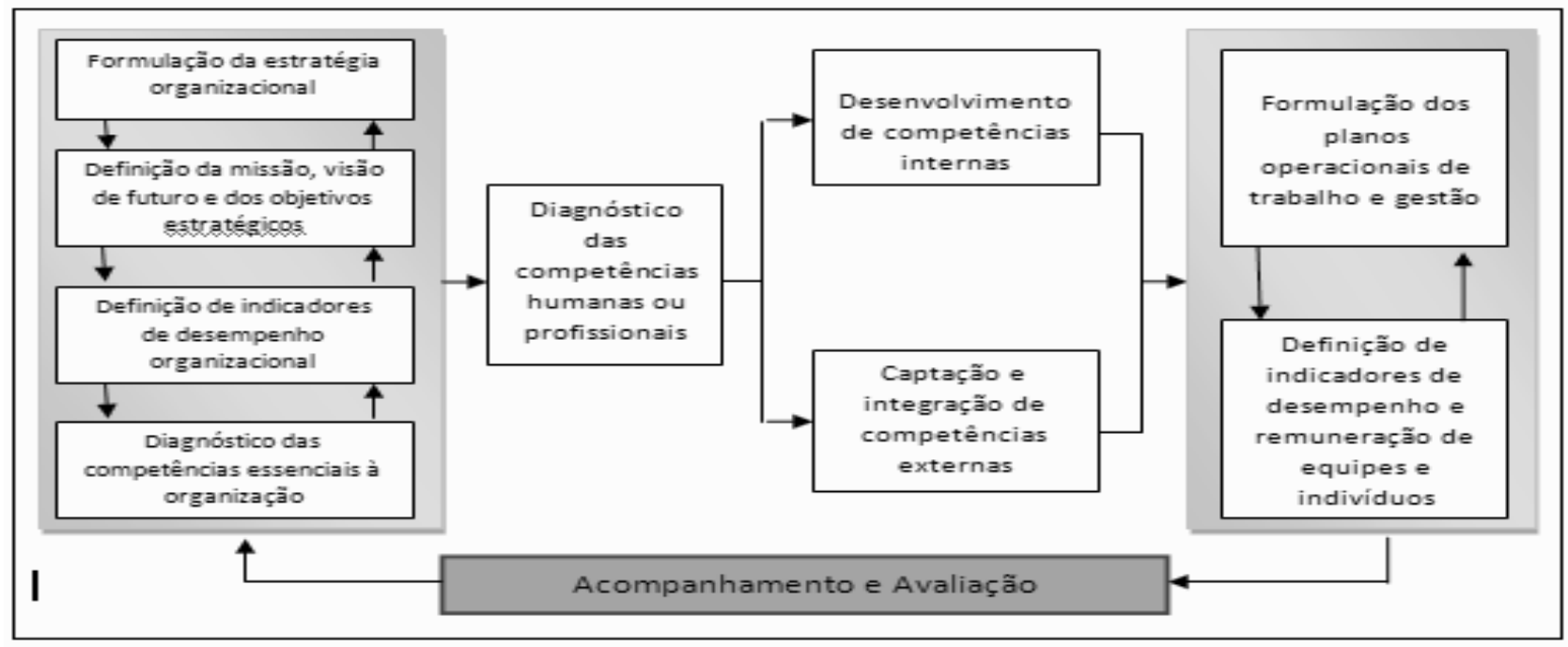

Fonte: Guimarães et al. (2001 apud CARBONE et al., 2009), com adaptações.

O modelo de gestão por competência, quando estruturado e inserido na organização, garante simplicidade e transparência de processos e informações, otimizando recursos. Facilita no direcionamento da retenção e no desenvolvimento profissional, potencializando o encontro de novos talentos para a empresa, além de diminuir custos, melhorando os investimentos. O modelo possui flexibilidade, podendo se adaptar a ações futuras de mudança de estruturação, de organização de trabalho e de tecnologia. Contribui para tornar a empresa justa, remunerando seus colaboradores de acordo com a agregação de valor de cada um (DUTRA, 2001).

Com a implementação do modelo, a organização tem significativo impacto nas suas ações de gestão de pessoas, refletindo assim nas pessoas de forma individual e, consequentemente, nos resultados organizacionais (CARBONE et al., 2009). Isso porque as estratégias organizacionais coligadas aos diagnósticos de competências auxiliam a empresa no planejamento das ações de gestão de pessoas, como já mencionado. Esse auxílio traz ganhos importantes para a organização como um todo, posto que as competências compõem a avaliação de desempenho que, por sua vez, servem como orientadoras para a educação corporativa - um dos subsistemas da gestão de pessoas - e seus processos de identificação das necessidades de aprendizagem. Essas necessidades só podem ser tangíveis à organização por meio do mapeamento das competências, pois é por ele que se consegue identificar as lacunas, e assim preenchê-las progressivamente (CARBONE et al., 2009).
O auxílio do modelo de gestão por competência à gestão de pessoas garante maior facilidade e clareza no processo de avaliação de desempenho e feedback, proporcionando tanto para avaliador quanto para avaliado um processo válido (LUSTRI; MIURA, 2005).

A gestão por competência auxilia também no processo de identificação e alocação de talentos mencionados por Carbone et al. (2009). Para eles, organizações que trabalham com o mapeamento das competências conseguem alocar melhor seus colaboradores, descobrindo talentos que anteriormente poderiam não ser utilizados de forma a propiciar seu melhor desempenho. Afirmam também que é possível recrutar e selecionar melhor seus futuros colaboradores, uma vez que pessoas pleiteadoras das vagas deverão possuir as competências pessoais e comportamentais exigidas para o cargo, de forma a suprir as competências essenciais à organização.

Outro beneficio mencionado pelos autores é no que tange à orientação e à gestão de carreira. Partindo do mapeamento de competências, as organizações conseguem conciliar suas necessidades às oportunidades profissionais, das quais dispõe aos seus colaboradores e às aspirações de crescimento de cada um.

Lustri e Miura (2005, p. 09) corroboram com esse pensamento quando afirmam, em seus estudos realizados em uma empresa nacional prestadora de serviços, que a gestão por competência emite "[...] clareza no direcionamento da carreira em virtude do conhecimento das competências valorizadas pela empresa". 
Carbone et al. (2009) mencionam ainda que organizações que passam a trabalhar com a gestão por competência conseguem remunerar seus funcionários de forma justa, proporcionando-lhes motivação.

Percebe-se então que todos os benefícios gerados pela gestão por competência, muito alinhados à gestão de pessoas, possuem um ponto em comum: os resultados organizacionais. O melhoramento dos processos de gestão de pessoas na organização refletirá essencialmente nos colaboradores, motivando-os a alcançarem resultados positivos, proporcionando melhores condições de trabalho e garantindo crescimento profissional. Por conseguinte, mantendo-os motivados, estima-se que os resultados organizacionais sejam satisfatórios, e que os objetivos estratégicos possam ser atingidos de forma eficiente e eficaz (CARBONE et al., 2009).

Assim como para a organização, existem benefícios para os colaboradores, conforme menciona Dutra (2001). Esse modelo agrega ganhos significativos, uma vez que é possível ao profissional obter crescimento na carreira pessoal, além de contar com condições claras e objetivas que facilitam a mobilidade entre carreiras abrangidas pelo modelo. Partindo do modelo, o profissional é remunerado de forma justa, recebendo o equivalente à complexidade das responsabilidades atribuídas a ele, estimulando seu autodesenvolvimento e a ampliação do espaço de atuação.

Le Bortef (2003 apud LUSTRI; MIURA, 2005) afirma que, considerando-se o contexto histórico, há a necessidade das organizações buscarem recursos humanos mais capacitados, devido à alta competitividade do mercado. Havendo essa necessidade, as organizações tendem a gerir pessoas de acordo com suas habilidades e conhecimentos. As competências assim tornam-se pontos críticos à organização, visto que seu conceito passa a ser mais adequado à gestão de pessoas, pois auxilia na mobilidade profissional vivida de fato nas empresas atuais.

Outros aspectos favoráveis ao modelo de gestão por competência, mencionados por Lustri e Miura (2005) em seus estudos é quanto à notoriedade dos objetivos e das estratégias organizacionais por todos os colaboradores, que assim passam a conhecer e a compreender melhor as suas contribuições à organização. As autoras mencionam também que colaboradores participantes do modelo de gestão por competência conseguem identificar suas próprias lacunas, avaliando onde há a necessidade de melhorar e desenvolver suas competências para alcançar resultados mais satisfatórios. Assim, as pessoas conseguem visualizar e entender as expectativas da empresa em relação a elas.

Dutra, Hipólito e Silva (2000) mencionam em seus estudos realizados em uma empresa de telecomunicação que um modelo de gestão por competência facilita o gerenciamento. Logo, para um gestor, a possibilidade de cometer injustiças torna-se praticamente nula, ajudando-o a conhecer melhor os seus subordinados. Para eles, outro fator importante observado nos estudos é em relação à gestão do desempenho, que se tornou mais simples, obtendo maior facilidade em orientar os subordinados. A carreira foi outro fator positivo, pois foi possível perceber uma maior oportunidade no crescimento profissional. Um dos pontos chave no estudo foi a aceitação de um modelo por competência pelos funcionários, que se mostraram receptíveis e confiantes, apostando em mudanças positivas.

Os autores concluem que a gestão por competência é uma alternativa real para estruturar as ações de recursos humanos, como foi observado na pesquisa realizada na empresa de telecomunicação, na qual afirmam que o modelo pode suprir as principais necessidades emergentes da gestão de pessoas, a fim de sobreviver em um mercado cada vez mais competitivo.

Para finalizar, Brandão e Babry (2005) afirmam que assim como empresas privadas, o serviço público vem procurando acompanhar as mudanças no mundo organizacional. O serviço público vem utilizando gestões, como a baseada nas competências, a fim de proporcionar alternativas de gestão flexíveis e empreendedoras, possibilitando melhorias na qualidade e na eficiência dos serviços prestados à sociedade. Assim, órgãos públicos, com o auxílio de um modelo de gestão por competência, começam a nortear as orientações profissionais, a avaliação de desempenho e o planejamento de carreira, entre outros processos.

\section{Procedimentos metodológicos.}

\subsection{Metodologia da pesquisa}

A presente pesquisa pode ser classificada como um estudo exploratório. Segundo Júnior (2003), ela está 
voltada para o fenômeno que se quer conhecer, quando o pesquisador não tem conhecimento das dimensões analisadas e busca um entendimento global do problema.

O método de abordagem do problema é predominantemente qualitativo, pois o que se almeja é compreender o caso estudado, e não focar em uma explicação. Não se procura o rigor da precisão numérica de uma análise quantitativa, mas sim ultrapassar esses limites para a compreensão dos resultados expostos (RAMPAZZO, 2004).

Para isso, também foi utilizado uma pesquisa bibliográfica para analisar o termo competência, apontar as estruturas e os principais benefícios ocorrentes do modelo de gestão por competência, bem como uma pesquisa documental para a análise de como a gestão vem sendo utilizada dentro do TCU. O entrelaçamento dessas informações facilitou a avaliação, o planejamento e a conduta da pesquisa (BENZ; NEWMAN, 1998; CRESWELL, 1994).

\subsection{Instrumentos}

Os instrumentos utilizados para o desenvolvimento da pesquisa foram:

1 Periódicos acadêmicos retirados de fontes como: Scielo, Anpad e Google Acadêmico, procurados a partir de palavras-chave como competências, gestão por competência e gestão de pessoas baseado em competências, bem como livros retirados de acervos, utilizando as mesmas palavras-chave;

2 Projeto de Revisão do Modelo de Gestão por Competência, atualizado em 13 de abril de 2011, cedido pelo TCU;

3 Entrevista semiestruturada, com o intuito de conseguir coletar as expectativas dos responsáveis pela elaboração do projeto de gestão por competência dentro do Tribunal;

\subsection{Participantes e procedimentos empíricos}

A entrevista foi realizada com os três principais nomes referentes ao projeto dentro do TCU. O primeiro entrevistado é servidor há quase quatro anos. Trabalha há dois com o projeto de gestão por competência e teve experiência com o tema em outro órgão. O segundo entrevistado é servidor do Tribunal há quase oito anos, tendo participado do projeto por todo esse período. Por fim, o terceiro entrevistado está no Tribunal há mais de quatro anos, participando do projeto desde então e também pos- sui experiência no assunto, trabalhando para outro órgão público.

A entrevista foi realizada de forma individual. As três entrevistas foram baseadas em onze perguntas iniciais que foram norteadoras do processo. As respostas foram registradas por meio de anotações e gravação pré-concedidas pelos entrevistados. O tempo médio estimado para a conclusão da entrevista individual foi de meia hora, sendo que as três entrevistas foram concluídas em duas semanas.

\subsection{Unidade de análise}

O órgão estudado foi o Tribunal de Contas da União - TCU. Dois pontos foram motivadores desse estudo. O primeiro, pelo TCU, um órgão da administração pública, adotar uma política de gestão de pessoas apoiada nas estratégias organizacionais, assim modificando vários processos e adotando outros, como o modelo de competências, algo além do que pode ser visto em outros órgãos públicos; o que, consequentemente, gera curiosidade. Outro ponto, pela então adoção do modelo em 2006, que não teve êxito. E pela iniciativa em 2009 de reestruturação para a adaptação do modelo. A persistência por parte do órgão remete à importância da sua implementação. Assim, este estudo se motivou a conhecer quais as expectativas das pessoas envolvidas no projeto de gestão por competência no TCU (BRASIL, 2011).

Como já mencionado, o TCU teve a sua primeira tentativa de implementação do modelo em meados de 2006. Essa implementação é resultado de inúmeras mudanças que até hoje ocorrem no Tribunal. O objetivo é alinhar os processos de gestão de pessoa aos objetivos e metas estratégicas do órgão (BRASIL, 2011).

A proposta inicial do modelo de competência surgiu por meio do Projeto Atena, em 2003. O projeto pretendia mapear os perfis dos profissionais, utilizando as competências profissionais, decorrentes das necessidades de alinhamento e adequação dos perfis às necessidades organizacionais (BRASIL, 2011.).

Após a sua primeira tentativa de implementação em 2006, feita por uma empresa de consultoria externa, o Instituto Sezerdello Corrêa (ISC), que foi instituído pela Resolução TCU no 19 de 09/11/1994, como uma unidade de apoio estratégico do TCU, e que desde o princípio auxilia na elaboração do projeto, identificou algumas di- 
ficuldades que precisavam ser sanadas para a eficiência do projeto. Percebeu-se a dificuldade nos processos de gestão de pessoas decorrentes da falta de uniformidade e de descrição das competências, bem como no atendimento teórico prático das competências, e no uso das escalas que, muitas vezes, não refletiam a realidade do Órgão e de suas unidades. (BRASIL, 2011).

Assim, após o ISC tomar a iniciativa de rever o modelo, sentiu-se a necessidade de um alinhamento entre ISC, que até dezembro de 2010 geria o modelo de gestão por competência, e a Secretaria de Gestão de Pessoas (SEGEP) do Tribunal (BRASIL, 2011).

O processo de revisão teve inicio com uma discussão do termo competência. Para o TCU, o termo passou a ser vista como "[...] a mobilização de conhecimentos, habilidades e atitudes do servidor, no contexto de trabalho, para individualmente ou em equipe, alcançar os resultados esperados pela organização" (BRASIL, 2011, p. 5).

É importante mencionar que as referências utilizadas pelo TCU para embasar o modelo utilizado partem de premissas americanas e francesas, como já mencionadas e explicadas neste artigo. Assim, autores como: Pedro Paulo Carbone, Hugo Pena Brandão e Joel de Souza

Figura 3: Trajetórias Profissionais TCU
Dutra, entre outros nomes renomados na área de gestão de pessoas e por competência, foram utilizados por se fundamentarem nessas premissas. Entretanto, o modelo empregado pelo TCU aborda principalmente aspectos mencionados por Dutra (2001), como pode ser visto na Figura 1 presente na revisão de literatura deste artigo.

Vale ressaltar que, mesmo o TCU utilizando o modelo de Dutra (2001) como o centro do projeto, ou seja, a forma como ele será atribuído às competências, o modelo proposto por Guimarães (2001 apud CARBONE et al., 2009), visualizado na Figura 2 da revisão de literatura, também é utilizado para nortear o processo de gestão por competência dentro do Tribunal.

O modelo utilizado pelo Tribunal conta com aspectos, tais como: agregação de valor, trajetória profissional e espaço ocupacional. Dessa forma, faz-se uma relação em que o espaço ocupacional (estágio de domínio da competência) demonstra qual é a trajetória profissional (ao ultrapassar cada trajetória o servidor agrega complexidade, responsabilidades, domínio de competências associadas e autonomia em decisões.) associada a um conjunto de entregas (comportamentos esperados pela organização) (BRASIL, 2011). Como pode ser visualizado na figura a seguir:

\begin{tabular}{|c|c|c|c|}
\hline Liderança e Gestão & $\begin{array}{l}\text { Controle Externo ou } \\
\text { Interno }\end{array}$ & Apoio Estratégico* & Apoio Administrativo \\
\hline $\begin{array}{l}\text { GE 2 } \\
\text { GE 1 }\end{array}$ & & & \\
\hline GT2 & CEL 3 & EST 3 & ADM 4 \\
\hline GT1 & CEL 2 & EST 2 & ADM 3 \\
\hline GOP 1 & CEL 1 & EST 1 & ADM 2 \\
\hline & & & ADM 1 \\
\hline
\end{tabular}

Fonte: Brasil (2011).

\subsection{Procedimentos de análise de resultados}

Depois de serem realizadas as entrevistas, as respostas foram transcritas em todos os seus detalhes. Posteriormente, foi criada uma tabela categorizando os termos chave referentes à expectativa, onde foi possível fazer uma análise de conteúdo, partindo do que foi obtido a partir das três entrevistas, agrupando comentários em cada uma das categorizações, de acordo com as frequências e valências respectivas. A frequência representa a quantidade de relatos encontrados em cada categoria, e a valência por sua vez, se cada relato agrega valor positivo ou negativo às categorias.

Ao final, discutiu-se o que foi encontrado na análise de conteúdo com o referencial teórico, de forma a fomentar novas discussões e alcançar os resultados deste artigo por meio do problema e do objetivo que se definem em identificar as expectativas dos servidores responsáveis pelo projeto de gestão por competência, apresentando as suas previsões de resultado desse modelo. 


\section{Resultados e discussão}

A composição da análise de conteúdo partiu de palavras-chave, selecionadas pela autora desta pesquisa de acordo com referências citadas na revisão de literatura. Sendo elas: Simplicidade e transparência: relacionado à comunicação, vislumbre de objetivos e ações dentro do Tribunal, de forma a proporcionar maior clareza tanto ao TCU, quanto aos servidores; Desenvolvimento profissional: ações facilitadoras para o desenvolvimento profissional dentro do Tribunal; Empresa justa: em relação ao deslocamento interno, alocação e desenvolvimento; Resultados organizacionais; Avaliação de desempenho; Definição e alocação de talentos; Motivação; Processos; Objetivos Estratégicos; Recursos Humanos mais capacitados; Resistência: em relação ao modelo de gestão por competência dentro do TCU; Facilitador do gerenciamento: gerenciar diferentes áreas do Tribunal de forma mais efetiva e eficaz; Nortear as orientações profissionais e Gestão de pessoas.

Assim, conseguiu-se identificar quais são as expectativas presentes em cada um dos entrevistados para a implementação do modelo de gestão por competência dentro do Tribunal. Foi possível, inclusive, perceber que algumas ações como alocação, desenvolvimento profissional, maior clareza e simplicidade, recursos humanos mais capacitados já podem ser vistos dentro do Tribunal. A maior expectativa agora está relacionada aos resultados agregados a todas essas ações para o Tribunal como todo.

Inicialmente, é importante mencionar que o modelo já começou a ser implantado em algumas áreas do TCU, principalmente na movimentação de servidores que se encontram em outros Estados (SECEX - Secretária de Controle Externo dos Estados), ou seja, a alocação de um Estado para o outro já vem sendo feita por meio das competências.

Um dos entrevistados mencionou que era habitual um servidor ser transferido de um Estado para o outro e quando chegava ao novo local de trabalho ele não estava apto para exercer aquelas funções, ou seja, não resolvia as necessidades da unidade. Após implementarem as competências nesse processo de alocação, verificou-se que os gestores identificavam quais as competências prioritárias e, por meio delas, acontecia a alocação dos servidores, evitando assim, a ociosidade do serviço e, consequentemente, uma melhora nos resultados.
Outra área que já utiliza o mapeamento das competências é a de liderança e gestão; um dos produtos mais ajustados feito pela consultoria externa, que sofreu poucas alterações na revisão do modelo. Para essa área, foi criada uma página on-line, na qual os servidores têm acesso a conteúdos respectivos a cada competência, que deve ser entregue em determinados períodos.

Ressalta-se que a implementação do modelo é algo demorado que requer muita orientação e feedback. Sendo assim, os três entrevistados são unânimes ao dizer que ainda há um longo caminho a percorrer, muitos desafios a serem vencidos e, principalmente, muitos objetivos a serem cumpridos.

Diante disso, o primeiro ponto a ser comentado é simplicidade e transparência, no qual percebe-se que os três entrevistados são categóricos quando afirmam que o modelo proporciona maior clareza e até mesmo simplifica na relação entre servidor e órgão. Ou seja, o que o Órgão precisa em termos de proatividade, de entregas para assim poder chegar aos resultados desejáveis e, em contrapartida, o que é necessário para que o servidor alcance os seus objetivos dentro do Órgão. Logo, o modelo proporciona um melhor direcionamento para a gestão de pessoas, já que o caminho tanto para o sucesso do alcance dos objetivos do Órgão, quanto para o sucesso do alcance dos objetivos do servidor já está traçado. Resta a cada um fazer a sua parte e esperar pelos resultados respectivos. A ideia fica mais clara pelo ponto de vista de um dos entrevistados, quando relata que:

Em gestão de pessoas o que você quer? Você quer, é ... direcionar comportamento, você quer modelar pessoas. E é muito fácil você passar mensagens dúbias, ambíguas. Agora, se você tem um elemento que é o norteador dos processos, você passa a mensagem clara, e ai você consegue de fato modelar comportamento.

Carbone et al. (2009) evidenciam essa ideia ao dizer que o modelo de gestão por competência, quando estruturado e inserido na organização, garante a ela simplicidade e transparência de processos e informações, otimizando recursos.

Sendo assim, uma das primeiras expectativas em relação ao modelo é conseguir clareza nas informações, auxiliando os processos de gestão de pessoas dentro do Tribunal, de forma a transmitir as informações necessárias sem qualquer tipo de ruído, obtendo assim resultados satisfatórios, fato observado nas áreas em que o modelo vem sendo implementado. 
O segundo ponto a ser comentado é a definição e a alocação de talentos. Um dos entrevistados relatou que:

Eu estou mudando a pessoa de trajetória, para liderança e gestão pra reconhecer a excelência dele na trajetória de controle externo. Então, são trajetórias diferentes, que consequentemente são competências diferentes, são conhecimentos habilidades e atitudes diferentes. Isso deixa a desejar. Se eu reconheço que a pessoa tem excelente trajetória, ela tem que ser premiada naquela trajetória.

Tal fato é visto na teoria proposta por Carbone et al. (2009) ao afirmarem que organizações que trabalham com o mapeamento de competências conseguem alocar melhor seus colaboradores, descobrindo talentos que anteriormente poderiam não ser utilizados de forma a propiciar seu melhor desempenho.

A afirmativa citada acima começou a ser evidenciada pelos responsáveis do projeto no Tribunal. Como já mencionado, alguns dos processos de alocação dentro do Tribunal, tal qual para a trajetória de liderança e gestão, de alocação de uma SECEX para outra e até mesmo alguns processos internos, ou seja, na própria sede, já são norteados pelas competências. Os resultados até agora, segundo os entrevistados, vêm se mostrando satisfatórios, tanto no auxílio aos processos de gestão de pessoas, bem como nos resultados dos trabalhos realizados.

Um exemplo citado por um dos entrevistados é com relação ao reconhecimento pela excelência de algum trabalho realizado. Para ele, um fato que acontece principalmente em órgãos da administração pública é que, muitas vezes, reconhece-se um servidor lotado na trajetória de controle externo, colocando-o na trajetória de liderança e gestão. Por muito tempo, observou-se que esse reconhecimento pode não ser positivo nem para o servidor e muito menos para o Órgão, tendo em vista que o servidor pode não apresentar a mesma produtividade anterior, assim como o Órgão não ter mais a eficiência de antes. A gestão por competência, por sua vez, pode vir a auxiliar nesse reconhecimento, uma vez que ela transmite clareza, e assim é possível vislumbrar se esse servidor que merece ser premiado tem as competências essenciais ou mínimas para compor a trajetória de liderança e gestão, posto que, do contrário, essa premiação deverá ocorrer na sua própria trajetória, até o momento de ele estar preparado e querer seguir para outra trajetória.
O modelo permite ao servidor enxergar quais são as suas possíveis trajetórias dentro do Tribunal. Sabe o que ele precisa fazer e como fazer para conseguir ser realocado e caminhar entre essas trajetórias. Assim, o Tribunal consegue um processo contínuo de incentivo e de motivação por parte desse servidor, o que, consequentemente, o tornará mais satisfeito, proporcionando melhores resultados ao Órgão.

Uma grande expectativa cerca a questão das orientações profissionais. O terceiro entrevistado menciona sobre o "servidor acomodado", uma característica comum, ligada à cultura imposta ao serviço público. Por esse motivo, o modelo no Tribunal tenta proporcionar aos servidores oportunidade de guiar a sua trajetória. E dizer quais as suas pretensões, qual o seu papel e qual a sua função dentro do TCU, como pôde ser vislumbrado quando um dos entrevistados diz: "ele pode saber o que é necessário e se desenvolver, preparar-se adequadamente."

Assim, o modelo proporciona ao servidor a oportunidade de gerir a sua carreira. Ele sabe que, para conseguir chegar a uma determinada área, ele deve fazer o que o Tribunal estipulou, assim ele estará investindo na sua carreira profissional e também no Tribunal. Com o modelo, o TCU estará instigando o servidor a não ficar parado, evitando o comodismo e galgando novos desafios. Até mesmo porque, o que se espera é conseguir junto ao modelo de gestão por competência o auxílio de uma avaliação de desempenho capaz de verificar se as entregas destinadas às trajetórias de cada competência estão sendo cumpridas e assim elaborar uma gestão das consequências.

Auxiliando nesse pensamento, Carbone et al. (2009), assim como Lustri e Miura (2005), acreditam que, por meio da gestão por competência é possível conciliar as necessidades da organização às oportunidades profissionais que ela dispõe aos seus colaboradores e às aspirações de crescimento de cada um deles. As autoras afirmam ainda que, em seus estudos realizados em uma empresa prestadora de serviços à autogestão, pôde ser visualizado o impacto positivo que ela proporcionou aos resultados organizacionais.

Dutra (2001), assim como Lustri e Miura (2005), compartilham pensamentos quando afirmam que é possível ao profissional obter crescimento na carreira pessoal, além de contar com condições claras e objetivas que facilitam a mobilidade entre as carreiras abrangidas pelo 
modelo. Conseguem ainda identificar suas próprias lacunas, avaliando onde há a necessidade de melhorar e de desenvolver suas competências para alcançar resultados mais satisfatórios.

Dessa forma, a autogestão mencionada pelos entrevistados está intimamente associada à alocação e as duas à questão da simplicidade e da transparência. São todas expectativas que conversam entre si. Assim, outro ponto a ser comentado é a avaliação de desempenho, que, como já mencionado, está associada principalmente à autogestão da carreira. Na opinião dos entrevistados, uma das maiores expectativas é conciliar a avaliação de desempenho ao modelo de gestão por competência no âmbito do Tribunal.

Para Carbone et al. (2009), as competências compõem a avaliação de desempenho, facilitando os processos de identificação das necessidades de aprendizagem. Assim, é possível conseguir identificar as lacunas e, consequentemente, preenchê-las progressivamente.

Acoplado a isso, Lustri e Miura (2005) observam que o modelo proporciona maior facilidade e clareza no processo de avaliação de desempenho e feedback, proporcionando tanto para avaliador quanto para avaliado um processo válido.

É possível perceber que as teorias citadas acima vão ao encontro do que foi mencionado pelos entrevistados, posto que estes afirmam que a avaliação de desempenho é uma parte fundamental para o acontecimento eficaz do modelo de gestão por competência, já que ela é responsável em identificar se as entregas necessárias estão sendo feitas dentro do Tribunal.

Um dos entrevistados foi categórico ao mencionar que a avaliação de desempenho é o centro do modelo de gestão de pessoas, que é o principal influenciado em relação aos resultados pelo modelo baseado em competências. Logo, para que os resultados possam surgir de forma mais expressiva e positiva, deve-se fazer uma avaliação que mensure se as competências estão sendo entregues corretamente. Duas respostas podem surgir. Uma positiva, de que as entregas estão sendo feitas de maneira a gerar os resultados esperados. Ou uma negativa, os resultados não estão sendo alcançados. Sabendo disso, fica mais fácil detectar o problema e corrigi-lo para que não volte a acontecer.
Entretanto, essa é uma fase ainda não alcançada pelo TCU. Uma fase esperada, quando a gestão por competência estiver atrelada e mensurada pela avaliação de desempenho. Como expõe um dos entrevistados ao dizer "que seria o "nirvana", o "melhor dos mundos" para o modelo..

Partindo de tudo o que já foi mencionado até aqui, pode-se inferir que o Tribunal, com a ajuda do modelo, terá funcionários mais capacitados para a realização das atividades necessárias para o seu funcionamento pleno. Assim, inicia-se o próximo ponto a ser abordado: recursos humanos mais capacitados.

Um dos principais objetivos do modelo de gestão por competência é o mapeamento das competências. Por meio dele, é possível identificar as competências pessoais de cada servidor, podendo assim vislumbrar os seus potenciais. Mediante esse mapeamento, o Tribunal consegue identificar os servidores certos para compor um determinado tipo de trabalho. Dois benefícios podem ser facilmente detectados aqui: o primeiro, com relação à maior satisfação do servidor que, certamente, será alocado em uma área de seu interesse, que ele se preparou para exercer; o outro, com relação aos resultados. O servidor satisfeito tende a apresentar resultados mais eficazes. Dessa forma, é possível perceber que o Tribunal terá servidores mais capacitados para exercerem as suas funções.

Um dos motivos mencionados neste artigo para as organizações buscarem recursos humanos mais capacitados se deu pela recente pressão do mercado, tornandose cada vez mais competitivo, como menciona Le Bortef (2003 apud LUSTRI; MIURA, 2005). Pode-se imaginar que a competitividade só acontece na iniciativa privada. No entanto, ela está presente também no serviço público. Para o TCU, ela está mais presente nos seus objetivos estratégicos, já que tem por finalidade mostrar à sociedade um órgão atuante e prestativo, capaz de exercer a função a que lhe foi imposta, o de fiscalizador de recursos públicos repassados à União.

Dessa forma, o Tribunal busca profissionais mais capacitados. Isso ocorre desde o processo seletivo, realizado por meio do concurso público, a alocação desses profissionais e o seu desenvolvimento. Como é possível perceber na fala de um dos entrevistados "se você consegue vislumbrar certo potencial, você pode capacitar antecipadamente esse servidor para futuras demandas ou futuras produções dentro do Tribunal.” 
Até agora foram mencionados assuntos tais como: simplicidade e transparência, orientações profissionais, avaliação de desempenho, recursos humanos mais capacitados. É possível perceber que todos eles trazem um ponto em comum: são partes que compõem os processos de gestão de pessoas.

Pode-se inferir, então, que os resultados apresentados até o presente momento influenciam diretamente os processos da gestão de pessoas. O que já tinha sido mencionado por este artigo e agora vem sendo confirmado.

Pretende-se que o modelo de gestão por competência oriente as ações da gestão de pessoas, conseguindo, assim, maior simplicidade e transparência em seus processos e nas relações entre servidores e Tribunal: facilitando o desenvolvimento profissional; definindo e alocando os servidores de acordo com os seus talentos e descobrindo novos talentos; norteando as orientações profissionais, por meio da autogestão, obtendo assim recursos humanos mais capacitados e aptos a exercerem as funções que lhes foram designadas; possibilitando a avaliação do desempenho dos servidores; premiando quando necessário e descobrindo as necessidades de aprendizagem; e fazendo do Tribunal um órgão justo. Dessa forma, os servidores se sentirão mais motivados, visto que os processos serão apresentados de forma clara e concisa, evitando possíveis resistências que muitas vezes surgem.

Espera-se então que, facilitando o gerenciamento dentro do Tribunal em virtude do modelo, os objetivos estratégicos possam ser supridos, alcançando a missão e a visão, e chegando aos resultados organizacionais esperados.

Conseguindo então articular os processos de gestão de pessoas, o TCU conseguirá alcançar os seus objetivos estratégicos, como é possível perceber na fala de um dos entrevistados: "Um desempenho que converse com os objetivos estratégicos do órgão. Que realize a missão dele e que o leve na direção da visão. Você executa a missão em busca dessa visão. E pra isso você precisa de desempenho diferenciado."

Para os entrevistados, o alcance dos objetivos estratégicos acontece de acordo com aquilo que o Tribunal estipula que deve ser feito, ou seja, quais as entregas necessárias. A partir do momento em que a gestão de pessoas é apoiada em um modelo coerente, fica mais fácil gerir os recursos humanos, ajudando-os a conseguirem efetivar e potencializar as suas entregas.

Lustri e Miura (2005) apoiam isso ao mencionar em seus estudos que, ao existir a notoriedade dos objetivos e estratégias organizacionais por todos os colaboradores, eles passam a conhecer e compreender melhor as suas contribuições à organização.

Dessa forma, quando há o alcance dos objetivos estratégicos, há, por conseguinte, o alcance dos resultados organizacionais, que, na realidade, é o espelho de todas as ações envolvidas na gestão baseada em competências. A gestão de competência é um processo de mudança organizacional. Para saber se as expectativas foram alcançadas e a mudança de fato contribuiu para o melhoramento daquilo que foi envolvido, é preciso avaliar os resultados finais, o que foi agregado de positivo, para então, futuramente, maximizar esses resultados sempre aprimorando, ou aquilo que demonstrou ser negativo, retomando ao inicio do processo para saná-lo, evitando futuros erros.

Como sugere Carbone et al. (2009), ao dizerem que, ao final do processo, devem ser feito um acompanhamento e uma avaliação dos resultados alcançados, comparando com aqueles que eram esperados. Compara-se também as mudanças sofridas após a implementação do modelo, e os resultados obtidos antes e depois de sua implementação. Durante essa avaliação, é verificado se a ações adotadas pela organização foram eficazes em promover e desenvolver as competências. Essa fase é o retroalimentador do sistema. É ela quem ajuda a subsidiar novas etapas do processo, garantindo informações capazes de movimentar o modelo de gestão por competência.

Junto ao alcance dos objetivos estratégicos, também se alcançam os resultados organizacionais como o ponto chave do modelo de gestão por competência, responsável por avaliar se ele está sendo ou não eficaz para o Órgão. E percebe-se que, para os responsáveis pelo projeto no Tribunal, as expectativas se voltam principalmente aos resultados; para eles, o modelo proporcionará “[...] uma atuação mais efetiva do TCU. Percebe é o Tribunal ocupando o lugar que lhe cabe. Não somente como um Órgão que controla o dinheiro posterior que é gasto, mas que atue de forma proativa, de forma pedagógica, atua fomentando o controle social." 
Como o modelo já começou a caminhar em determinadas áreas do TCU, alguns resultados já podem ser visualizados de forma muito positiva e satisfatória. Dessa forma, a expectativa para um resultado maior assim que o modelo tomar notoriedade de fato, o que, infelizmente, ainda pode demorar, segundo eles, mas, que se espera alcançar, só aumenta como pode ser visto em seus relatos, ao mencionar que se espera "o funcionamento pleno do Tribunal."

\section{Considerações finais}

Diante do que foi apresentado, foi possível de forma categórica responder ao problema deste artigo: Quais as expectativas dos servidores responsáveis pelo projeto em relação aos resultados futuros da implementação do modelo de gestão por competência?

As expectativas envolvem principalmente as ações da gestão de pessoas, esperando assim que o modelo possa dar suporte à gestão de pessoas, de forma a proporcionar servidores mais capacitados, motivados e que entendam as suas funções dentro do Tribunal. Tendo os processos de gestão de pessoas integrados, espera-se o alcance dos objetivos estratégicos, ou seja, que a missão e a visão do Tribunal possam ser atingidas, demonstrando que o TCU é um órgão de excelência refletido em seus resultados organizacionais.

Tendo alguns processos já norteados pelas competências, expressando resultados satisfatórios, os responsáveis pelo projeto relatam que as expectativas para o modelo dentro do Tribunal são animadoras e esperadas ansiosamente, para que todos os estudos e comprometimento pelo modelo até agora comecem a render bons frutos.

Para conseguir responder ao problema, foi necessário o cumprimento dos objetivos específicos, que foram alcançados de forma satisfatória. Com a ajuda de uma revisão da literatura acerca do tema competência, foi possível compreender melhor o assunto, além de poder visualizar na prática o que foi encontrado em livros e artigos, observando a funcionalidade do modelo dentro do TCU. Para responder de fato ao problema, foi realizada uma entrevista com os três nomes responsáveis pelo projeto de gestão por competência dentro do Tribunal. A partir das entrevistas, foi possível observar que aquilo que os autores renomados no assunto afirmavam em suas obras de fato pode acontecer na prática.
Ainda que o Tribunal esteja em uma fase inicial do modelo, alguns resultados podem ser visualizados e as expectativas até o final da implementação do modelo são promissoras.

Por se tratar de um assunto ainda novo para o mundo organizacional, espera-se que os resultados encontrados sirvam de subsídios para outros estudos. Por ter tido como justificativa a curiosidade de estudar um órgão público com gestão à frente daquelas vistas nos demais órgãos da administração pública, este estudo pretende servir como um incentivo para outros órgãos, bem como empresas que queiram trabalhar com uma gestão baseada em competências.

O presente artigo sugere ainda, que novos estudos sejam realizados no TCU assim que o modelo for colocado em prática efetivamente, para saber se essas expectativas aqui apresentadas de fato se concretizaram, proporcionando a eficiência e o funcionamento pleno do Tribunal. Sugere-se também a realização de novos estudos na área, provocando maiores discussões sobre um tema novo e que poderá acarretar mudanças significativas no mundo organizacional, como colocado em outros estudos, e também mencionado pelos responsáveis do projeto no Tribunal, de que as competências surgem como base da gestão de pessoas, norteando todos os seus processos, a fim de alcançar resultados melhores e se garantir em um mercado cada vez mais competitivo.

\section{Referências}

BENZ, J. N.; NEWMAN, J. Qualitative-quantitative research: a false dichotomy. Southern Illinois: University Press, 1998.

BITENCOURT, Claudia et al. (Org.). Gestão contemporânea de pessoas: novas práticas, conceitos e tendências. 2. ed. Porto Alegre: Bookman, 2010.

BRANDÃO, Hugo Pena. Aprendizagem, contexto, competência e desempenho: um estudo multinível. 2009. $345 \mathrm{f}$. Tese (Doutorado)-Curso de Psicologia Social do Trabalho e das Organizações, Departamento de Instituto de Psicologia, Universidade de Brasília, Brasília, 2009.

BRANDÃO, Hugo Pena; BABRY, Carla Patrícia. Gestão por competência: métodos e técnicas para mapeamento de competências. RSP, Brasília, p. 179-194, 01 abr. 2005. Disponível em: <http://xa.yimg.com/kq/ groups/24137146/1575141967/name/Texto+8+-+Gest\% $2 \mathrm{~B} \% \mathrm{C} 3 \% \mathrm{BAo}+$ por+compet $\% 2 \mathrm{~B} \% \mathrm{C} 2 \% \mathrm{ACncias}+$.pdf $>$. Acesso em: 25 mar. 2012. 
BRANDÃO, Hugo Pena; GUIMARÃES, Tomás de Aquino. Gestão de competência e gestão de desempenho: tecnologias distintas ou instrumentos de um mesmo construto? RAE, São Paulo, v. 41, n. 1, p. 8-15, jan. 2001. Disponível em: <http://www.scielo.br/scielo. php?pid=S0034-75902001000100002\&script $=$ sci_ arttext>. Acesso em: 01 abr. 2012.

BRASIL. Tribunal de Contas da União. Plano Estratégico: construindo o TCU do futuro. 2011 - 2015. Disponível em: <http://portal2.tcu.gov.br/portal/page/portal/TCU/ planejamento_gestao/planejamento2011/index.html>. Acesso em: 28 mar. 2011.

BRASIL. Tribunal de Contas da União. Revisão do Modelo de Gestão por Competência. Brasília: TCU, 2011.

CARBONE, Pedro Paulo et al. (Org.). Gestão por competências e gestão do conhecimento. 3. ed. Rio de Janeiro: FGV, 2009.

DUTRA, Joel de Souza et al. (Org.). Gestão por competência: um modelo avançado para o gerenciamento de pessoas. São Paulo: Gente, 2001.

DUTRA, Joel de Souza. Competências: conceitos e instrumentos para a gestão de pessoas na empresa moderna. São Paulo: Atlas, 2010.

DUTRA, Joel de Souza. Gestão de pessoas por competência: um novo modelo de gestão ou modismo. MAMES, São Paulo, p. 1-9, 27 jan. 2008. Disponível em: <http://www.memesgestao.com.br/jportal/portal. jsf? post=3529>. Acesso em: 31 mar. 2012.
DUTRA, Joel de Souza; HIPÓLITO, José Antonio Monteiro; SILVA, Cassiano Machado. Gestão de pessoas por competência: o caso de uma empresa de telecomunicações. RAC, Curitiba, v. 04, n. 01, p.161176, 30 jan. 2000. Disponível em: <http://www.scielo.br/ scielo.php?pid=S1415-65552000000100009\&script $=$ sci_ arttext>. Acesso em: 31 mar. 2012.

FERNANDES, Bruno Henrique Rocha; FLEURY, Maria Tereza. Modelo de gestão por competência: evolução e teste de um sistema. PUCRS, Porto Alegre, v. 18, n. 02, p. 103-122, 30 jul. 2007. Disponível em: <http:// revistaseletronicas.pucrs.br/ojs/index.php/face/article/ view/2676>. Acesso em: 27 mar. 2012.

GIL, Antonio Carlos. Como elaborar projetos de pesquisa. 5. ed. São Paulo: Atlas, 2010.

JUNIOR, Joseph F. Hair et al. Fundamentos em métodos de pesquisa em administração. São Paulo: Artmed, 2003.

LUSTRI, Denise A.; MIURA, Irene K. Gestão por competência: uma abordagem sistêmica. USP, São Paulo, p. 1-11, maio 2005.

RAMPAZZO, Lino. Metodologia científica: para alunos dos cursos de graduação e pós-graduação. 2. ed. São Paulo: Loyola, 2004. 